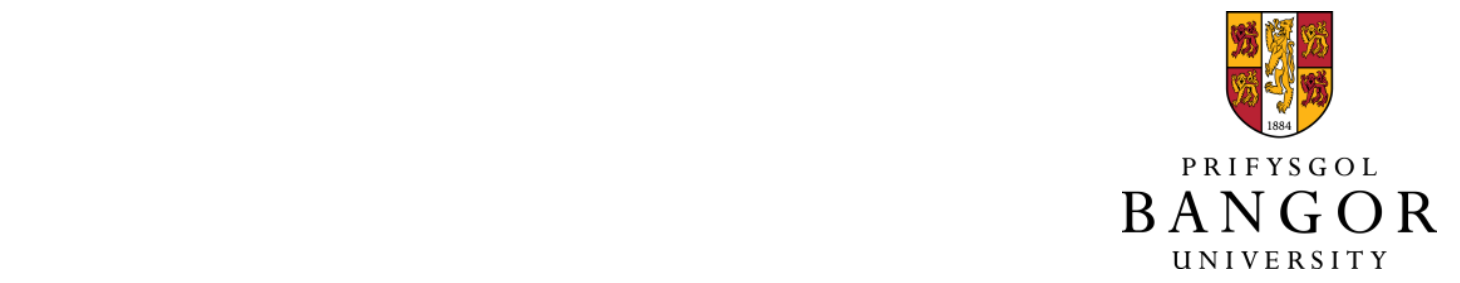

Phylogeny and diversification of mountain vipers (Montivipera, Nilson et al., 2001) triggered by multiple Plio-Pleistocene refugia and high-mountain topography in the Near and Middle East

Stümpel, Nikolaus; Rajabizadeh, Mehdi; Avci, Aziz; Wüster, Wolfgang; Joger, Ulrich

\title{
Molecular Phylogenetics and Evolution
}

\author{
DOI: \\ 10.1016/j.ympev.2016.04.025
}

Published: 01/08/2016

Peer reviewed version

Cyswllt i'r cyhoeddiad / Link to publication

Dyfyniad o'r fersiwn a gyhoeddwyd / Citation for published version (APA):

Stümpel, N., Rajabizadeh, M., Avci, A., Wüster, W., \& Joger, U. (2016). Phylogeny and diversification of mountain vipers (Montivipera, Nilson et al., 2001) triggered by multiple Plio-Pleistocene refugia and high-mountain topography in the Near and Middle East. Molecular Phylogenetics and Evolution, 101, 336-351. https://doi.org/10.1016/j.ympev.2016.04.025

\footnotetext{
Hawliau Cyffredinol / General rights

Copyright and moral rights for the publications made accessible in the public portal are retained by the authors and/or other copyright owners and it is a condition of accessing publications that users recognise and abide by the legal requirements associated with these rights.

- Users may download and print one copy of any publication from the public portal for the purpose of private study or research.

- You may not further distribute the material or use it for any profit-making activity or commercial gain

- You may freely distribute the URL identifying the publication in the public portal ?
}

Take down policy

If you believe that this document breaches copyright please contact us providing details, and we will remove access to the work immediately and investigate your claim. 
Phylogeny and diversification of mountain vipers (Montivipera, Nilson et al. 2001) triggered by multiple Plio-Pleistocene refugia and high-mountain topography in the Near and Middle East

Nikolaus Stümpel ${ }^{1}$, Mehdi Rajabizadeh ${ }^{2}$, Aziz Avcl $^{3}$, Wolfgang Wüster ${ }^{4}$, Ulrich Joger $^{5}$

${ }^{1,5}$ State Museum of Natural History Braunschweig, Gaußstraße 22, Braunschweig D-38106, Germany, nikolaus.stuempel@gmx.de (corresponding author), u.joger@3landesmuseen.de

${ }^{2}$ Department of Biodiversity, International Center for Science, High Technology \& Environmental Sciences, Kerman, Iran, khosro.rajabizadeh@gmail.com

${ }^{3}$ Adnan Menderes University, faculty of art and science, Department of Biology, Aydın, Turkey, rhynchocalamus@gmail.com

${ }^{5}$ School of Biological Sciences, Environment Centre Wales, Bangor University, Bangor, LL57 2UW, UK, w.wuster@bangor.ac.uk

\section{Abstract}

The Near and Middle East is a hotspot of biodiversity, but the region remains underexplored at the level of genetic biodiversity. Here, we present an extensive molecular phylogeny of the viperid snake genus Montivipera, including all known taxa. Based on nuclear and mitochondrial data, we present novel insights into the phylogeny of the genus and review the status of its constituent species. Maximum likelihood methods revealed a montane origin of Montivipera at 12.3 Mya. We then analyzed factors of mountain viper diversity. Our data support substantial changes in effective population size through Plio-Pleistocene periods. We conclude that climatic oscillations were drivers of allopatric speciation, and that mountain systems of the Near and Middle East have strongly influenced the evolution and survival of taxa, because climatic and topographical heterogeneities induced by mountains have played a crucial role as filters for dispersal and as multiple refugia. The wide diversity of montane microhabitats enabled mountain vipers to retain their ecological niche during climatic pessima. In consequence the varied geological and topographical conditions between refugia favoured genetic isolation and created patterns of species richness resulting in the formation of neoendemic taxa. Our data support high concordance between geographic distributions of Montivipera haplotypes with putative plant refugia.

\section{Keywords}

Montivipera, Near East and Middle East, phylogeny, divergence times, phylogeography, allopatric speciation 


\section{Introduction}

In recent decades, biota of the Mediterranean Basin have been studied extensively to understand the determinants of present-day biodiversity. The patterns revealed by multiple authors indicate that biodiversity of the Mediterranean region has had a turbulent history triggered by climatic changes. In particular, the deterioration of warm, moist Tertiary climates during the Plio-Pleistocene appears to have had profound effects on faunal and floral compositions.

There is ample evidence for Plio-Pleistocene climatic oscillations as drivers for glacial refugia, hotspots of genetic diversity, postglacial re-colonization routes and so on (e.g. Hewitt, 1996; 2000; 2004a; 2011). Climatic oscillations during the Plio-Pleistocene caused expansion or regressive fragmentation of fauna and flora (e.g. Hewitt, 2000; 2004a; Varga and Schmitt, 2008) at both global (e.g. Bennett, 1997) and regional (Svenning and Skov, 2007) scales. Owing to regional differences in landforms, different species respond differentially to climatic changes. In central and northern Europe, biota underwent latitudinal shifts over long distances, changing organismal abundances and species compositions dramatically, including through extinction of the Pleistocene megafauna (e.g., Hofreiter and Stewart, 2009). However, Pleistocene climatic cycles also profoundly affected the distribution and composition of Mediterranean biota (Taberlet et al., 1998; Weiss and Ferrand, 2007). In particular, for thermophilic animals, southern regions of the Mediterranean acted as refugia, by providing suitable habitats during adverse climate periods (e.g. Ursenbacher et al., 2006a,b Joger et al. 2007): refugial areas accumulated populations of species through both range expansions and contractions resulting in latitudinal clines in species richness (e.g. Hewitt, 2004b). As a result, the European peninsulas in the Mediterranean (Iberia, Italy and the Balkans) are rich in endemic reptiles (see Cheylan and Poitevin, 1994), because refugia appear to have reduced extinction rates and, through their isolation, favoured the emergence of new evolutionary lineages (e.g. Hungerer and Kadereit, 1998). This is even more applicable to the circum-Mediterranean region as a whole, which constitutes one of the world's major biodiversity hotspots (Médail and Myers, 2004).

One of the goals of phylogeographic examinations is to infer the historical and contemporary forces that have shaped the genetic architecture of populations and closely related species (Avise, 2009) through the use of gene genealogies. Numerous studies have shown that dramatic changes of environmental conditions have left still-detectable traces in the genome of current biota. These genetic consequences of climatic oscillations have been studied for many organisms in the European part of the Mediterranean Basin. In contrast, although the ecosystems of the Near and Middle East harbor a similarly rich biological diversity, a much more substantial proportion remains partially undocumented (Ansell et al., 2012), especially at the level of genetic diversity (Krupp et al., 2009), 
and phylogeographic studies remain rare, impeding our understanding of the processes that have shaped the biodiversity of the region.

The Near and Middle East have been described as either a center of origin with active speciation (e.g. Hungerer and Kadereit, 1998), or as Plio-Pleistocene refugia for relict biota (Médail and Diadema, 2009). Extremely relevant to evolutionary biogeography is the high topographic relief of the region, creating a variety of heterogeneous Mediterranean oro-biomes, which allowed biota to retain their ecological niches during climatic pessima by altitudinal range shifts. Thus, geomorphological settings conserve regional genetic diversity as refugia and initiate vicariant allopatric speciation, because of distributional dissection. These effects have been shown to be relevant for European biota in high mountain systems (e.g. Schmitt, 2009). Generally, geographic vicariance is considered to be the most common mode for speciation (e.g. Futuyma, 1998; Barraclough and Vogler, 2000; Turelli et al., 2001). However, allopatric speciation driven by vicariance is not simply a geographic event (Wiens, 2004). Wiens illustrates how niche conservatism drives allopatric lineage splitting in mountain systems. Intrinsic physiological factors constrain species to their ecological niches over time and reduce their fitness outside of the niche (Holt and Gaines, 1992; Holt, 1996). The process impedes gene flow (Wiens, 2004) and creates phylogenetic pattern in ecological data (Wiens et al., 2010).

Many groups of reptiles make ideal model organisms for the study of the impact of past climatic changes on patterns of species diversity and distribution, due to their low vagility and often narrow ecological niches. Moreover, reptiles are often important or even dominant components of the fauna of Mediterranean and semi-arid ecosystems. The Near and Middle East contain a high diversity of reptile taxa, including a number of endemic lineages. Among other groups, the Near and Middle East are notable for harboring the highest diversity of true vipers within Eurasia. Eurasian vipers have been the subjects of intensive surveys of phylogeny (e.g. Lenk et al., 2001; Wüster et al., 2008; Ursenbacher et al., 2008) and phylogeography (e.g. Ursenbacher et al., 2006a,b; Barbanera et al., 2009; Ferchaud et al., 2012; Zinenko et al., 2015). However, while the overwhelming majority of papers focus on the genus Vipera, only scant data are available about the Near and Middle Eastern endemic genus Montivipera.

Mountain vipers (Montivipera) are excellent model organisms to study the impact of past climatic oscillations for allopatric speciation in the mountain systems of the Near and Middle East. These snakes are endemic to the Near and Middle East, from the Aegean coast of Anatolia and neighboring islands to the highlands of central Iran. Most taxa have a montane distribution above an elevation of $1400 \mathrm{~m}$ a.s.l. and are mainly confined to oro-Mediterranean habitats, which expanded and retracted with climatic cycles since late Miocene. As sit-and-wait predators with a short and stout physiognomy, mountain vipers have a low vagility/movement capability (e.g. Mebert et al. 2015) that increases the effects of physical vicariance and isolation by distance. 
Mountain vipers have a comparatively recent history of discovery: seven out of ten taxa have been described since the 1960s, and new taxa might be remain to be discovered (Rajabizadeh et al., 2011). Based on analyses of immunological distances (Herrmann et al., 1992) and DNA-DNA hybridization experiments (Nilson et al., 1999), Montivipera was initially separated from Vipera as a subgenus, and later raised to full genus rank (Joger, 2005). Montivipera consists of two allopatrically distributed species complexes (Nilson and Andrén, 1986). The xanthina-complex includes the monotypic species xanthina Gray, 1849, bornmuelleri Werner, 1898, wagneri Nilson \& Andrén, 1984, bulgardaghica Nilson \& Andrén, 1985 and albizona Nilson, Andrén \& Flärdh 1990, and is restricted to Anatolia and the Levant. As the eastern counterpart, species of the raddei-complex are known from Armenia, Azerbaijan, Iran and Turkey. Four species with two subspecies have been described: raddei Boettger, 1890 with the nominate subspecies and raddei kurdistanica Nilson \& Andrén 1986, latifii Mertens, Darevsky \& Klemmer, 1967, albicornuta Nilson \& Andrén, 1985 and recently kuhrangica Rajabizadeh, Nilson \& Kami, 2011.

The history of the taxonomy and systematics of the genus Montivipera was marked by a heated scientific debate about species concepts and phenotype diversity (see Schätti et al.,1991;1992; Nilson and Andrén, 1992). In the absence of conclusive data, this controversy created much confusion and a persistent lack of consensus on the systematic situation of the group. As a result, different herpetologists adopted different classifications on the sole basis of personal preference (e.g. David and Vogel, 2010; Phelps, 2010). Legitimately, Wüster et al. (1997, p.335) stated that "Until a full analysis of the population phylogeny of these forms is carried out, using large samples and preferably a wide range of characters, and in particular molecular markers, the situation is likely to remain confused." We here follow Wüster et al. (1997) and provide the first molecular phylogenetic and phylogeographic analysis of the genus Montivipera, based on extensive sampling through most of its range. In addition to the academic interest of the group, mountain vipers are of considerable medical importance due to their wide distribution in the Middle East, causing many envenomations in rural regions with morbidity and mortality in Turkey (Ozay et al., 2005). However, Montivipera venoms and the level of compositional variation in them (Chippaux et al., 1991) have not been thoroughly characterized pharmacologically, and specific or evidence based polyvalent antivenoms for these taxa are only available for members of the raddei-complex (Razi Institute Teheran). Understanding the phylogeny and species diversity within the genus represents an essential underpinning for rigorous studies of venom variation and antivenom effectiveness.

The first goal of this study is thus to review the state of Montivipera systematics. Using a dense sampling embracing all known taxa and a multilocus mitochondrial and nuclear dataset to overcome the limitations of studies based solely on mitochondrial DNA (Galtier et al., 2009), we reconstruct the phylogenetic history of the genus. Based on a multilocus analysis with four nuclear and three 
mitochondrial genes we test the monophyly of the xanthina-and-raddei-complexes, determine its constituent taxa and test, if the taxa bornmuelleri, wagneri, bulgardaghica and albizona are monophyletic.

The second objective is to ascertain the determinants of present-day lineage diversity in time and space. We analyze, whether Montivipera has a montane origin, and if Plio-Pleistocene climatic oscillations have left a spatially arranged genetic imprint on the genome of mountain vipers, and, more specifically, whether population size changes over their demographic history are still detectable in the current genome. Finally, we discuss, whether the observed genetic diversification is the result of isolation in Quaternary glacial refugia.

Our study illustrates the importance of Near and Middle Eastern mountain systems for allopatric speciation, and recovers for the first time the phylogenetic history within the genus Montivipera on the basis of nuclear and mitochondrial genes.

\section{Material and Methods}

\subsection{Specimen acquisition and molecular protocols}

A total of 115 viper samples were gathered from colleagues, zoological institutions, or were donated with permission from museum collections (Tab. A.1).

Genomic DNA was extracted from muscle, scale clips or exuvia using DNeasy Blood \& Tissue Kit (Qiagen) according to the manufacturer's instructions. We amplified three protein-coding mitochondrial (mt) genes (CYTB, COX1, ND5) from 115 viper samples with 2489 alignment positions totall. As nuclear markers, we amplified four nuclear (nc) genes (RAG1, BACH1, MKL1, MC1R) with 5013 alignment positions totall. All of them have been previously used for multilocus species delimitation in Squamates (e.g. Vidal and Hedges, 2005; Lynch and Wagner, 2010; McVay and Carstens, 2013; Tolley et al. 2013) and show polymorphism within and between closely related taxa. We designed specific PCR primers for most loci amplified in this study (Tab. A.2).

For the amplification of target genes the TaKaRa Ex Taq ${ }^{\text {TM }}$ PCR reaction system was used, containing $2.5 \mu \mathrm{l}$ 10XBuffer, $2 \mu \mathrm{l}$ dNTP Mix, $2.5 \mathrm{U}$ enzyme, $1 \mu \mathrm{l}$ of 10 pmol primer each, $1 \mu$ l genomic DNA, filled up with $\mathrm{dH}_{2} \mathrm{O}$ to $25 \mu \mathrm{l}$ volume in total. Polymerase chain reaction was carried out, using the

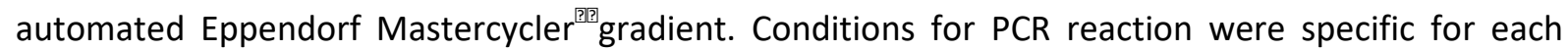
gene and are given in Table A.3. After PCR products were cooled down and stored until use at $8{ }^{\circ} \mathrm{C}$. Dye terminator cycle sequencing was set up according to suppliers' instructions (DTCS Quick Start Kit, Beckman Coulter) in a two step thermal reaction with 30 cycles of $96^{\circ} \mathrm{C} 20 \mathrm{~s}, 60^{\circ} \mathrm{C} 4 \mathrm{~min}$. For Dyeterminator removal we used the Agencourt CleanSEQ system (SPRI-technology), and ran the samples on a Beckman Coulter CEQ 8000 sequencing apparatus. All new DNA sequences generated for this study were submitted to GenBank (FJxx-FJxx). 


\subsection{Sequence alignment and mtDNA phylogenetic analyses}

Mitochondrial and nuclear sequences were edited and assembled using SEQUENCHER (Gene Codes). Gene fragments were aligned separately using ClustalW (Thompson et al., 1994) implemented in Bioedit 7.0.9 (Hall, 1999).

Heterozygous sequences were identified visually by checking for double peaks (point mutations) in the electropherograms. Alleles were reconstructed for each specimen, using the software PHASE v. 2.1.1 (Stephens et al., 2001; Stephens and Scheet, 2005) by conducting two independent runs under the default settings. Then the most likely haplotype pairs for each individual were chosen. The program PartitionFinder (Lanfear et al., 2012) was used to determine the best partitioning strategy and substitution models for the analysis. However, to identify the most appropriate models of sequence evolution for each gene and dataset, we tested also other partitioning strategies using MrModeltest 2.3 (Nylander, 2004).

The phylogenetic history of mt-genes was reconstructed, using Bayesian inference (BI) and Maximum likelihood (ML). For Bayesian inference (BI) we used MrBayes 3.1.2 (Ronquist and Huelsenbeck, 2003) and partitioned the analysis by genes and codon positions. We ran the analyses with one cold and three heated chains $\left(\mathrm{MC}^{3}\right)$ for 50 million generations sampling every $1000^{\text {th }}$ generation and discarding the first $25 \%$ of the trees as burn-in. Convergence was estimated in Tracer v1.5 (Rambaut and Drummond, 2007) and observed with the convergence diagnostic parameters implemented in MrBayes.

For maximum likelihood we used the software PhyML version 3.0 (Guindon et al., 2010), under the GTR model with four substitution rate categories and 1000 non-parametric bootstrap replicates.

We specified Macrovipera as the outgroup for all analyses, as they are likely to be the sistergroup of Montivipera (Lenk et al., 2001; Wüster et al., 2008, Stümpel and Joger, 2009).

\subsection{Species tree reconstruction and molecular dating}

We used a coalescent-based method to estimate a time calibrated species tree from four nuclear (RAG1, BACH1, MKL1, MC1R) and three mitochondrial (CYTB, COX1, ND5) genes, using a Bayesian framework implemented in the computer software *BEAST v. 1.8.0 (Drummond et al., 2012). Unlike concatenated analyses, which shoehorn all loci into a single tree topology, this approach enables multiple independent loci to be analysed simultaneously within a framework that accounts for gene tree incongruence resulting from incomplete lineage sorting. This approach is preferable to concatenation, which can lead to poor performance of standard phylogenetic estimates (Kubatko and Degnan 2007).

Species tree approaches assume OTUs to be reproductively isolated, so that shared haplotypes are the result of retention of ancestral haplotypes rather than ongoing gene flow. It follows that any 
group that has an independent evolutionary history, can be designated as 'species' for the analysis. Here, Montivipera xanthina has a substantial, well supported phylogeographic mt-DNA structure that coincides with differences in the phenotypic appearance and ecological adaptations between the populations of geographical regions (see below). We argue that this suggests the presence of a taxonomically unrecognized diversity and consequently treated the populations of Montivipera xanthina suggested by the mtDNA gene tree as independent evolutionary entities.

Molecular dating is critically affected by the quality of calibration points. Calibrations at internal nodes are usually based on the fossil record, which is largely incomplete and biased (Lieberman, 2002; Hedges and Kumar, 2004). Its use and interpretation is often problematic. According to Gandolfo et al. (2008) fossil calibration errors may be caused mainly by five factors: (1) fossil preservation, (2) taxonomic assignment of the fossil, (3) identification of fossil homologies, (4) sampling effort, and (5) fossil age determination. Especially in terrestrial environments, in which the fossil record is poorer, identifications at the species level are difficult (Padian et al., 1994). Consequently the availability of reliable calibration dates is traditionally restricted to few model organisms (Benton and Donoghue, 2007). Most viper fossils are isolated vertebrae, so that their taxonomic identification is problematic and relationships between extant and extinct species are in many cases unclear (Szyndlar and Rage, 1999). Head (2005) pointed out that ontogenetic variation in snake vertebrae is not well understood. In fact, the size of vertebrae is a character for taxonomic assignment of fossil vipers (Szyndlar and Rage, 1999). Consequently, the fossil record of Eurasian vipers does not provide enough verified evidence to date their cladogenesis.

For all of these reasons, we have used secondary calibrations of robust divergence time calculations to improve the precision and accuracy of time estimates. Any node of a robust primary divergence time calculation can be used as a secondary calibration point in a separate analysis, if there are no known biases (Hedges and Kumar, 2004). Stümpel (2012) computed a chronogram based on 50 amino acid sequences of complete mt-genomes, representing the full diversity of amniotes. In order to avoid fossil calibration errors inside viperids Stümpel dated the pedigree with 10 prominent tetrapod calibration points of Szyndlar and Rage (1990), Rage et al. (1992), Evans (2003), Müller and Reisz, (2005) and Benton and Donoghue (2007), using relaxed clock models. Based on these calculations, extant species from Montivipera and Macrovipera shared their last common ancestor (MRCA) at 15.3 Mya. Following lithological-palaeogeographic maps of Popov et al. (2004) the divergence time correlates with a long standing isolation of "Asia Minor" during the Langhian, between 16 and 15 Mya. The second calibration point we used, is the branching point between extant species of the Montivipera xanthina- and Montivipera raddei-complexes. Calculations of Stümpel (2012) date the timing of divergence at 10.7 Mya. However, the tectonic event that fits the palaeobiogeographical reconstruction of oriental vipers, and which may have acted as vicariant 
event, was the opening of a marine seaway along the Bitlis and Eastern Anatolian Fault zones in the middle Serravallian (13-12.2 Mya) (Stümpel, 2012). Consequently we used both tectonic events as calibration points to date the cladogenesis of the species tree. The initial divergence between Montivipera and Macrovipera was modeled with a normal distribution with a mean of 15.5 Mya and a standard deviation of 0.5 Mya, providing a 95\% confidence interval of 14.68 and 16.32 Mya. For the split between species of Montivipera xanthina- and Montivipera raddei-complexes we used a normal distribution with a mean of 12.6 Mya and a standard deviation of $1.2 \mathrm{Mya}$, giving a 95\% Cl of $10.63-$ 14.57 Mya.

The analysis was run for 600 million generations sampling every $3000^{\text {th }}$ generation, of which the first $25 \%$ were discarded as burn-in. To test the most appropriate partitioning strategy and substitution models for the analysis, we used the program PartitionFinder (Lanfear et al., 2012), applying partitions to the first/second and third codon for every gene.

To account for lineage-specific rate heterogeneity we used a Log-normal relaxed clock model and specified a birth-death process for modeling the dynamical process of speciation and extinction. Convergence statistics were monitored by effective samples sizes (ESS), analyzing the run in Tracer version v1.5 (Rambaut and Drummond, 2007). A consensus tree with divergence times was obtained from the 150,000 trees after discarding the first $25 \%$ as burn-in.

\subsection{Mitochondrial phylogeography}

For estimating the phylogeographic history we used statistical methods, implemented in the software PhyloMapper $1 \mathrm{~b} 1$ (Lemmon and Lemmon, 2008), which allows testing of a priori hypotheses. We first tested the phylogeographic association between phylogenetic and geographic distance for the mt-data matrix (CYTB, COX1, ND5) within each group after optimizing all parameters and then generating the null distribution by performing 10,000 randomizations. Significance of the test statistics rejects the null hypothesis that no association exists between geographic proximity and genealogical proximity within the clade. We then tested, if the individuals of each species complex tend to migrate in a non-random direction, using the overall directionality test as described by Lemmon and Lemmon (2008). To estimate the geographic location of the ancestors of the raddeiand xanthina-complex we calculated the locations of ancestors and estimated likelihood surfaces. We initially performed the estimates for a wide geographic range, using a low resolution factor and subsequently constrained the geographic grid for the final analyses. For the species complex of Montivipera xanthina we constrained the latitude from 35.0 to 40.5 and the longitude from 32.0 to 40.0, and for the species complex of Montivipera raddei we applied a latitude from 35.0 to 40.0 and a longitude from 44.0 to 52.0 , using a resolution of 0.3 in each group. All analyses were optimized by 10,000 replications.

\subsection{Neutrality tests and demographic analyses}


In order to detect a population's departures from equilibrium conditions, which may result from changes in population size, selection or gene flow, we used mt-DNA (CYTB,COX1,ND5) to calculate nucleotide diversity for each clade in addition to Tajima's D (Tajima, 1989) and Fu's Fs (Fu, 1997), under the neutral model. For historically stable populations, both $\mathrm{D}$ and Fs would be expected to be close to zero. Negative values of both $D$ and Fs would be indicative of recent population expansion, whereas positive values would be expect from a recent population bottleneck or from negative selection (Slatkin and Hudson, 1991; Rogers and Harpending, 1992; Charlesworth et al., 1995). Significance was assessed for both statistics by comparison with data simulated under a constant population size model, with significant $P$ values indicating rejection of the hypothesis of constant population size.

Population expansions have also been shown to leave particular signatures in the distribution of pairwise sequence differences. Unimodal and smooth mismatch distributions indicate panmictic populations, which undergo sudden range expansions (Slatkin and Hudson, 1991; Rogers and Harpending, 1992). In contrast, multimodal mismatch distributions suggest structured or diminishing population and ragged distributions indicate a stable and widespread population (Excoffier et al., 1992; Rogers and Harpending, 1992; Rogers et al., 1996; Excoffier and Schneider, 1999). Statistically significant differences between observed and simulated expected distributions were evaluated with the sum of the square deviations (SSD) and Harpending's raggedness index (RI), with significant $P$ values indicating rejection of the recent expansion hypothesis (Slatkin and Hudson, 1991; Rogers and Harpending, 1992). All analyses were performed using Arlequin v.3.1 (Excoffier et al., 2005).

To visualize changes in effective population size through time, we also inferred the demographic history of mountain vipers, using the extended Bayesian skyline plot (EBSP), as implemented in the Bayesian phylogenetic software BEAST (Drummond and Rambaut, 2007). The coalescent-based approach permits the analysis of multiple unlinked loci, enabling the rate and pattern of the evolutionary process to vary among loci. For both phylo-groups we performed two independent runs with 500 million generations for the bornmuelleri-clade (sampling every 3000 iterations) and 800 million for the xanthina- and raddei-clade (sampling every 3500 iterations). Results of each run were visualized using Tracer v1.5 (Rambaut and Drummond, 2007) to ensure stationarity and convergence had been reached, and that effective sample sizes (ESS) were higher than 200.

\section{Results}

\subsection{DNA sequence characteristics and phylogenetic results}

The concatenated mt-DNA matrix with 111 individual Montivipera DNA sequences and 2489 aligned positions (825 bp COX1, 1062 bp CYTB, 602 bp ND5) is characterized by 424 invariable, 178 polymorphic and 150 parsimony informative sites with 58 unique haplotypes totally. 
The nuclear data set embraces 270 Montivipera sequences, with 5013 alignment positions (2481 bp RAG1, 1105 bp BACH1, 777 bp MKL1, 650 bp MC1R) 43 polymorphic sites and59 unique sequences. Bayesian inference $(\mathrm{BI})$ and Maximum Likelihood $(\mathrm{ML})$ analysis of mt-DNA data produced concordant trees with considerable phylogenetic structure with distinct geographic associations (Fig. 2). Within the genus Montivipera the $\mathrm{BI}$ and $\mathrm{ML}$ genealogies support a sister-group relationship between the $M$. raddei- and the $M$. xanthina-complexes, with maximal statistical robustness and an uncorrected $\mathrm{p}$ distance of 0.107 . Haplotypes of the M. xanthina-complex segregate into two evolutionary clades with considerable divergences $(p$-distance $=0.069$ ). The eastern bornmuelleri-clade embraces the nominal taxa M. bornmuelleri, M. wagneri, M. bulgardaghica, M. albizona and a new taxon from Syria, which is separated by a p-distance of 0.028 from its sister taxa bulgardaghica and albizona. The bornmuelleri-clade has a monophyletic origin and its evolutionary lineages are separated by a maximum p-distance of 0.040 . The Anatolian xanthina-clade displays unexpectedly deep phylogeographic structure, suggesting long standing evolutionary isolation between groups, with higher p-distances (up to 0.056) than between the species of the bornmuelleri-clade. The common ancestry of the Anatolian populations is not well supported, suggesting the possibility of alternative genealogical relations (Fig. 2). However, each evolutionary lineage within the Anatolian clade is supported by maximal posterior probabilities and bootstrap values, with specimens from western Taurus in basal position, which are the sister-group of populations from Lycia and those from the Aegean coast.

In contrast to the high genetic structure of the xanthina-complex, we found only 16 unique mt-gene sequences among the raddei-complex, with a maximum genetic distance of $p=0.029$, indicating a historically young radiation. Haplotypes of the nominal taxon $M$. raddei kurdistanica are paraphyletic and also a common ancestry of $M$. albicornuta is statistically not well supported. Montivipera kuhrangica represents a separate evolutionary lineage, having a common ancestry with $M$. raddei. As expected the nuclear data set of Montivipera has a low variability with a maximal genetic distance of $p=0.0203$. Measures of the nuclear genetic distances confirm a more recent origin of the raddeicomplex and an older divergence of the xanthina-complex. The genetic distance of the Montivipera xanthina-complex ( $p$-distance $=0.0201)$ is 6 -fold higher than within the raddei-complex ( $p$-distance $=$ $\mathrm{p}=0.0032$ ).

\subsection{Species tree and molecular dating}

Post run diagnosis parameters of Tracer observed high effective sample sizes (ESS) and indicated that runs of the *Beast analyses converged.

The topology of the time calibrated multilocus species tree (Fig. 3) from the combined data set of nuclear and mitochondrial genes is congruent with the mt-genealogies obtained with MrBayes and PHYML and strongly supports a sister relationship between the Montivipera xanthina and the $M$. 
raddei-complex. Species of the xanthina-complex segregate into two clades with high Posterior Probabilities for a monophyletic origin of the bornmuelleri-clade. The relatively low support (PP 0.83) for the xanthina-clade suggests contradictory topologies with a possible paraphyletic origin of $M$. xanthina (Fig. 3). Divergence times support a late Miocene diversification of the $M$. xanthinacomplex. Populations of $M$. xanthina from the Taurus Mountains were identified as the oldest evolutionary lineage, which split off from its sister-group 5.2 Mya ago, and are thereby older than basal lineages within the bornmuelleri-clade. In contrast, divergence time estimates derived from sampled raddei populations were considerably closer to the present and have a Pliocene origin.

\subsection{Mitochondrial Phylogeography}

We found significant evidence for phylogeographic association in the M. xanthina- and the $M$. raddeicomplex at the $\alpha=0.001$ level (Tab. 2) and in the analyzed clades individuals tend to migrate in an non-random direction (overall directionality test: $p<0.001$ ).

We then estimated the geographic locations for the ancestors of the $M$. xanthina- and $M$. raddeicomplexes (Fig. 4). According to the analysis the mountain vipers of the xanthina-complex had their origin in the Anatolian Taurus Mountains (latitude 37.94, longitude 34.78, InL -381.33). Present haplotype distributions suggest a colonization of early ancestors mainly in east-west directions. Montivipera bornmuelleri from the Levant is the only recent population that indicates an ancestral colonization advance also to southern territories. Despite their spatial proximity, xanthina populations from Greek and Turkish Thrace go back to different dispersal events and do not share a common ancestor (Fig. 1).

The origin with the maximum likelihood estimate for the basal ancestor of the raddei-complex is located in the Persian Alborz Mountains (lat 35.06, long 49.18, InL -145.99).

\subsection{Population genetic analyses and historical demography}

Extended Bayesian skyline plots (EBSP) of the bornmuelleri- and xanthina-clade indicate a substantial population size change over their demographic history. Both clades had maintained high population size during Pleistocene glaciations of Northern hemisphere (Fig. 6). The EBSP of the xanthina-clade is bimodal with a broad peak between 2.8 and 1.6 Mya during late Piacenzian and Gelasian and a second peak in current times. In contrast, the bornmuelleri-clade reached its highest population between 1.2 and $0.4 \mathrm{Mya}$, when the xanthina population decreased to its all-time low. Since the Middle Pleistocene, the EBSP reveals a rapid decrease of the bornmuelleri-clade. In recent times the population started to increase slightly to current size. Populations of the M. raddei-complex (Fig. 7) were constant over long time periods and decreased around 116.000 years ago with End of Eemian warm phase and beginning of Tarantian stage of upper Pleistocene. The negative population trend turned 8.000 years ago and started to increase to the present day. 
Mismatch frequencies were calculated separately for the xanthina-, bornmuelleri- and the raddeiclade (Fig. 5). The shapes of the observed distributions deviate from a smooth unimodal pattern simulated under a sudden expansion model. Mismatch distributions have multimodal characteristics for all groups. In the raddei-complex the mismatch distribution has a high frequency of sequence pairs with low mismatch counts, indicating a shrinking or declining $N_{\mathrm{e}}$. Thus the associated Raggedness-Index is high for the bimodal distribution in raddei and much smaller for the multimodal distributions of xanthina and bornmuelleri. The variances (SSD) and Harpending raggedness index (RI) indicate that the observed distributions differ significantly from the distributions expected under the model of population expansion in all groups for SSD. For the raggedness index significance was only assessed for bornmuelleri. Fu's Fs and Tajima's $D$ are positive and differ from zero except for raddei. In concordance with the EBSP, high values for $F s$ and $D$ suggest a recent population bottleneck or negative selection in bornmuelleri and xanthina. However, test statistics for Tajima's $D$ and Fu's Fs cannot reject the null hypothesis $\left(H_{o}\right)$ that the sample of DNA sequences were taken from a population with constant effective population size (Tab. 1).

\section{Discussion}

\subsection{Mitochondrial genealogy uncovers hidden genetic diversity within Montivipera}

Our mitochondrial based phylogeny is a continuation of Stümpel et al. (2009) and represents the first study that includes all known taxa. The results provide significant new insights into the evolutionary history of mountain vipers. Previous mt-genealogies of Lenk et al. (2001) considered only three OTU's of mountain vipers and revealed a paraphyly of the Montivipera xanthina-complex, with $M$. raddei being closer to wagneri than xanthina. A CYTB based Maximum-Parsimony tree of Garrigues et al. (2005) with six OTUs of mountain vipers revealed the species of the xanthina-complex as a monophyletic assemblage, but without resolving their relations, because of low statistical support and a basal polytomy.

Our $\mathrm{BI}$ and $\mathrm{ML}$ genealogies support a sister relation between the raddei-complex and the xanthinacomplex with maximal statistical robustness, previously suggested by Nilson and Andrén (1986) based on morphological data and revealed with mt-marker by Garrigues et al. (2005). The monophyly of both complexes coincides with considerably differences in scalation, of which the circum-ocular ring, separating the supraocular from the eye, is most conspicuous (Nilson and Andrén, 1986).

Our phylogenetic inference showed that the xanthina-complex consists of two monophyletic groups, which correspond to east Anatolia (bornmuelleri-clade) and west Anatolia (xanthina-clade). Within the east Anatolian clade, we found bornmuelleri to be the most basal taxon. After the description of Vipera bornmuelleri Werner, 1898 as full species, it was synonymized with Vipera lebetina xanthina by Schwarz (1936), until Mertens (1967) resurrected the mountain viper from Lebanon as valid 
species under the assumption that Daboia palaestinae belongs to the "Rassenkreis" (species complex) of xanthina. This taxonomic position remained largely undisputed and most herpetologists (e.g. Joger, 1984; Brodmann, 1987; Golay et al., 1993) followed Mertens (1967). Only Schätti et al. (1991) doubted its validity and synonymized the populations from the Levant with xanthina, without granting them any taxonomic status. Golay et al. (1993) treated bornmuelleri as a subspecies of xanthina. Our mitochondrial genealogy strongly supports bornmuelleri as an independent evolutionary lineage, which belongs to the east Anatolian clade and has no common ancestry with xanthina, as suggested by Schätti et al. (1991).

Montivipera bornmuelleri is the sister taxon of the nominal taxa wagneri, bulgardaghica and albizona, which have a common ancestry. Montivipera wagneri was collected in 1846 by Moritz Wagner in the vicinity of Lake Urmia. Until its rediscovery by Teynié (1987) only the single female holotype was known (Nilson and Andrén, 1984). Today Wagner's mountain viper is only known from a small isolated exclave around the Aras river catchment in east Anatolia (Joger et al. 1988). Recently Göçmen et al. (2014) reported new localities of mountain vipers extending their range in Anatolia. However, in combination with the distinct morphology (Joger et al., 1988) and considerable differences in blood protein analyses (Herrmann et al., 1987), our results validate the populations from the Aras region as full species M. wagneri.

The sister-group of wagneri embraces the two nominal species bulgardaghica and albizona. The discourse about their systematics is discussed page by page in Schätti et al. (1991). Both taxa are restricted to the Taurus Mountains, but their distribution is only known from few individual localities and detailed sampling locations from the few caught specimens have never been published. However, the possibility of a parapatric contact zone between bulgardaghica and albizona exists and was discussed by Schätti et al. (1991). Our analyses show that haplotypes of M. bulgardaghica are nested within albizona and do not support the species status of albizona. The nearest populations of M. albizona are known from Tahtalı Dağları (Teynié, 1991) and Dibek Dağları (own observations), less than 200 km from Bolkar Mountains. Interestingly Schätti et al. (1991) mention a specimen caught in Kar Boğaz, which displayed a coloration that could be a morphological indicator for genetic contact between both taxa. Our data confirm this hypothesis. One specimen from the type territory, which was morphologically identified as bulgardaghica, shares an albizona haplotype.

Due to homoplasies in color pattern Bettex (1993) supposes albizona to be synonymous with wagneri, and Phelps (2010) treats bulgardaghica as conspecific with bornmuelleri. A specimen from the Syrian coastal Mountains near Slanfah (صــــ (صـف) ), formerly identified as M. xanthina by Sindaco et al. (2006), represents a new taxon basal to bulgardaghica.

Our mitochondrial genealogy confirms the statement of Nilson and Andrén (1986) and of Nilson et al. (1990) that M. xanthina is the closest relative of the four east Anatolian mountain vipers, which 
represents a divergent evolutionary lineage. Following Nilson and Andrén (1986), M. xanthina is also characterized by autapomorphies, such as ten supralabials and high number of subcaudals. However, the monophyly of xanthina (s.str.) is statistically significant in the MrBayes analysis, but is less robustly supported by the species tree of *BEAST.

Within M. xanthina our mt-genealogy recovers unexpected high levels of genetic diversity with a well supported phylogenetic structure. This is unexpected, as $M$. xanthina displays comparatively low variability in external morphology within its rather large range, as Nilson and Andrén (1986) note. Phenotypes do not display eye-catching differences in coloration or pattern, like $M$. wagneri and $M$. albizona, or a distinctive dorsal pattern like M. bornmuelleri. However, the unexpected cryptic genetic diversity revealed here suggests the presence of unrecognized taxa (Stümpel and Joger, 2009). Nilson and Andrén (1986) performed a hierarchical cluster analysis based on morphometric characters for species of the genus Montivipera and found considerable intraspecific variation within M. xanthina, but the results were not consistent for both sexes, and the authors distinguished, without drawing taxonomic conclusions, two subgroups (a northern and a southern xanthina) below the subspecies level. Their findings partially support the substantial genetic structure within xanthina.

In our data set the M. raddei-complex is a genetically relatively homogenous lineage, with the lowest haplotype diversity within the mountain vipers, possibly indicating their historically young radiation. The recently described species M. kuhrangica (Rajabizadeh et al., 2011) is the sister taxon of $M$. raddei and reflects the very incomplete knowledge of the distribution area, especially in the southern Zagros Mountains.

Given the poor exploration and the large geographic distance to the next populations of raddei (s. I.) it seems possible that unknown haplotypes may have been overlooked. Obst (1982) treats the taxa latifii and raddei as diverging populations of the same species, and Schätti et al. (1991) added also albicornuta to the synonyms of raddei. Nilson and Andrén (1986) hypothesized albicornuta and latifii to have a common ancestor. Our phylogenetic inference revealed latifii as a separate evolutionary lineage, which is confirmed by its distinctive ecological adaptation to alpine habitats in the Alborz Mountains (Mertens et al., 1967; Andrén and Nilson, 1979). Samples assigned to the subspecies raddei kurdistanica are scattered throughout the raddei-complex.

\subsection{Speciation and divergence times}

A key aim of this study was the molecular dating of important nodes for the reconstruction of biogeographical histories. For estimating rates of molecular evolution in a tree, nodes must be fixed to a time scale. Key means of clock calibration are fossil data, providing minimum constraints on the timing of lineage divergence events (Benton and Ayala, 2003; Benton and Donoghue, 2007). It is obvious that the quality of the fossil record has a large impact on the inferred divergence times of 
the pedigree. Eurasian vipers have a very poor fossil record and the taxonomic identification of fossils is often problematic. However, according to Antunes and Rage (1974) and Szyndlar and Rage (1999) oriental vipers of the genera Macrovipera or Montivipera appeared in the European fossil record for the first time in the lower Miocene (MN 3, 22.1 - 17 Mya). But the single vertebra from Lisboa, which is the evidence for the first appearance, could not be assigned with absolute taxonomic confidence. For the following Mammal period of the Neogene (MN 4, 17 - 16 Mya) Szyndlar and Rage (1999) claim that oriental vipers were already widespread in Europe and remained so until the Pleistocene, embracing a time period of at least 15 Mya. However, molecular divergence times do not confirm an early Miocene origin of Macrovipera and Montivipera. To date divergences among Colubroidea, Wüster et al. (2008) used a mitochondrial data matrix, mainly calibrated with fossil snake calibration points. According to the authors' analysis, Macrovipera was separated from Montivipera about 11 Mya ago, considerably younger than our results. The taxonomic affinity and/or stratigraphic age of calibration points used by Wüster et al. (2008) were doubted by Lukoschek et al. (2012), who demonstrated that the use of mitochondrial-only data by Wüster et al. (2008) may have inflated the ages of distal nodes relative to basal ones due to the saturated third codon position of mtDNA loci. Consequently Lukoschek et al. (2012) corrected the split between Montivipera vs. Macrovipera of Wüster et al. (2008) to younger ages - even less compatible with the estimates presented here. Szyndlar and Rage (1999) note that a distinction between fossil species of Macrovipera and Montivipera is hardly possible. Given the uncertainty of taxonomic identification it seems likely that extinct lineages and members of the stem-group were pooled by Szyndlar and Rage (1999) and may thus bias biogeographic hypotheses and systematic assignments.

To be free from circularity derived from the biased fossil record of snakes, we used secondary calibration points of Stümpel (2012), which were calculated using protein sequences of complete mtgenomes and are in concordance with vicariant events in the Tethyan realm and confirm the divergence times for the MRCA of Viperidae and Viperinae published by Wüster et al. (2008).

The topology of the multilocus *BEAST chronogram (Fig. 4) is congruent with the mitochondrial genealogy resulting from the MrBayes run. Nodes of the combined analysis of mtDNA and nuclear loci suggest a late Miocene (12.3 Mya) origin for the MRCA of Montivipera. The time frame correlates with a prominent tectonic event in the Middle East, the uplift of the Turkish-Iranian plateau to an elevation of 1.5-2 km a.s.I. (Şapaş and Boztepe-Güney, 2009). Along with the increase of elevation, climatic, spatial, biotic and evolutionary factors changed. The most obvious is the generally linear decrease in temperature, which decreases by an average of approximately $0.68{ }^{\circ} \mathrm{C}$ for each $100 \mathrm{~m}$ increase in elevation (Barry, 2008), so that the Turkish-Iranian plateau cooled down by approximately 10.2 to $13.6^{\circ} \mathrm{C}$ due to the uplift. Other abiotic factors like air pressure, solar radiation and humidity change predictably along the montane gradients. These determinants are well known to impact 
species richness (McCain and Grytnes, 2010) and are thus likely to have strongly influenced organismal communities and habitats in the Near and Middle East. Flora and fauna respond to these changes in their speciation and extinction rates. We propose this scenario as a driver for the Montivipera stem-group to adapt to mountainous conditions. The diversification of the xanthinaclade began in the early Pliocene at 4.7 Mya, as already hypothesized by Nilson and Andrén (1986). It is worth reiterating that this group was considered as monotypic until recently. The relatively old origin suggests extensive cryptic diversity. Recent species of the bornmuelleri-clade are of considerable younger age and have their origin in the late Pliocene. Based on immunological distances Herrmann et al. (1987) determined an age of less than 5 Mya for the MRCA of the bornmuelleri-clade. Wüster et al. (2008) estimated the taxa Montivipera xanthina having separated from Montivipera albizona approximately 4 Mya ago.

Despite the late Miocene origin of the raddei and xanthina stem-group, the most extant evolutionary lineages emerged not before the Pleistocene, except of the Lycian and Taurus lineages, which are of considerable older age. The absence of old lineages within the raddei-complex suggests a massive loss of lineage diversity through time. The global climate system experienced drastic changes from the middle Eocene to the present with global cooling and an overall increase of seasonality (Mosbrugger et al., 2005), which resulted in numerous shifts in the distribution and abundances of species (Hewitt, 2004a). However, Avise et al. (1998) calculated that $57 \%$ of the recent herpetofauna goes back to Pleistocene speciation events. The same time frame is mentioned by Veith et al. (2003) and Plötner et al. (2010) as relevant for the speciation of Anatolian anurans. Besides the climatic effects we could identify geological settings in Anatolia that are likely to have been relevant for lineage differentiation of Montivipera populations. The river Göksu Nehri, breaking the Taurus Mountains between the cities Mut and Silifke, is a barrier for montane biota. The valley bottom, with an elevation of less than $250 \mathrm{~m}$ a.s.l., is a barrier for dispersal of montane organisms, dividing Montivipera populations into an eastern (bornmuelleri-) and a western (xanthina)-clade. Beyond that, the tectonic evolution of the Isparta Angle might have triggered the isolation of the basal xanthina lineage from its sister-group. The Isparta Angle is a junction between the Aegean and Cyprus arcs, with a long-term polyphase deformation history, which is characterized by a massive EW compression, resulting in the N-S orientation of main structural lines (e.g. Van Hinsbergen et al., 2010; Poisson et al., 2011 and references therein). The inner Isparta Angle hosts several basins and lakes, which might constitute barriers to the dispersal of montane xanthina populations. Evolutionary lineages east of the Isparta Angle (Isparta, Geyik Dağı) are clearly separated from the West Anatolian lineages (Lycia, Aegean). 


\subsection{Phylogeography, population genetic analyses and historical demography}

Descriptive summary statistics and inferential methods of both $\mathrm{mt}$ and ncDNA are congruent and support substantial changes in effective population size of mountain vipers through time (Fig. 6). Based on our data, we argue that climatic oscillations during the Pleistocene, together with the high relief Near and Middle Eastern mountain systems, were key drivers of lineage diversity of mountain vipers.

Mountain vipers are spatially constrained to montane habitats, especially the taxa of the raddei and bornmuelleri-clades, which inhabit exclusively an elevational zone between 1400 and $2800 \mathrm{~m}$ a.s.l. We hypothesize the stem-group of Montivipera to have originated in oro-biomes, adapting to a seasonal climate and a diurnal lifestyle. The spatial hypothesis that Montivipera has a montane origin, is supported by the Likelihood estimates (center of origin), which reveal a montane origin of both the MRCA of xanthina-complex and the MRCA of the raddei-complex. In addition, the phylogenetic results (Fig. 2) show that the most basal and oldest lineages are invariably distributed in mountainous habitats, outnumbering lowland populations, which are of considerably younger age and nested deep within otherwise montane clades. Today species of the East Anatolian bornmuellericlade are ecologically confined to oro-Mediterranean habitats between 1400 and $2500 \mathrm{~m}$ a.s.l. In the Taurus Mountains the zone corresponds to the Cedrus-Abies forests (Querco-Cedretalia libani) outlined by the range of the Astragalo-Brometalia (Parolly, 2004). Evolutionary lineages of the xanthina-clade have a broader ecological amplitude distributed from sea level up to $2000 \mathrm{~m}$ a.s.l. The ultimate causes of why some lineages of the west Anatolian xanthina-clade display more plasticity remain unclear. However, we argue that the ancestral ecological trait is montane and adaption to lowland habitats occurred secondarily.

Our data indicate that the populations suffered substantial changes in effective population size over time. Growth and decline of populations can be associated with two relatively abrupt climate transitions, the onset of major northern hemisphere glaciations at approximately 2.7 Mya and the mid-Pleistocene transition (at approximately $900 \mathrm{ka}$ ), when the dominant periodicity of glacial response changes from 41 to $100 \mathrm{kyr}$ (Milankovitch, 1941; Paillard, 2001). This historical pressure on natural systems could have shaped species ranges and been the driver for demographic processes. EBSP indicate that ancestors of the xanthina and the bornmuelleri-clades responded differently to the change of environmental conditions. The xanthina-clade expanded during the warm phase of the Pliocene ('Green House effect'), but reached maximum population size at the beginning of the Pleistocene. During the climatic reorganization and the end of the Pliocene warm period (5-3 Mya ago) ancestors of the xanthina-clade must have successfully adapted to the changing abiotic and biotic conditions. During the continuous cooling of earth climate and the switch in the frequency of the astronomical Milankovitch cycles, ancestors of the xanthina-clade responded with a negative 
population growth rate, due to the deterioration of environmental conditions. Finally, the xanthinaclade shows evidence of population growth at the end of the Pleistocene, presumably as a result of the increase in available habitats for this warm, lowland-adapted species during the current interglacial.

Unlike in the xanthina-clade, evidence from EBSP indicates that ancestors of the bornmuelleri-clade increased population sizes during the Pleistocene, and had the adaptive capacity to use the ecological opportunities arising from Pleistocene climate oscillations through adaptive responses such as cold tolerance. Similarly, the bornmuelleri-clade shows no evidence of late Pleistocene population expansion, which is to be expected for a species inhabiting cool, high altitude habitats, which may have shrunk and become restricted to higher elevations as a result of late Quaternary climatic warming. In contrast populations of the raddei-complex collapsed from 116,000 to 8,000 years ago, coinciding with the final glacial episode of the Pleistocene (Tarantian), supposedly because of late Pleistocene hyperaridity. Pollen records from Lake Urmia in Iran give evidence that the lack of moisture supply during last glaciation changed the herbaceous vegetation to a xerophytic Artemisia and grass steppe (Djamali et al. 2008). In Iran the late glacial to early Holocene transition is marked by the expansion of deciduous forests (Djamali et al. 2008), indicating the increase of paleoenvironmental moisture supply and the extension of suitable habitats with an increasing population size of $M$. raddei ancestors.

Mountains have a high richness of different climatic zones and microhabitats. On a larger scale, this richness is primarily related to the change of abiotic factors along the altitudinal gradient and, on a more local scale, by slopes facing different geographic directions. In a spatio-temporal scenario, different microhabitats are very dynamic in terms of their distribution at different elevations at different times, but stable in terms of their continued existence within the mountain system. They thus enable species to retain their ecological niches during climatic changes by means of changes in their elevational distribution. The local range or 'biogeographical stasis' is therefore linked to capacity of the mountain range to provide the required microhabitat of the species despite changes in overall climatic conditions (Médail and Diadema, 2009). As a result of the elevational shifts, the habitats of montane species became restricted during global warming, because eco-zones shift to higher elevations, resulting in loss of available surface area. Conversely, climatic cooling shifts the range of acceptable ecological conditions back to lower altitudes and formerly isolated populations probably became connected again. In mountainous regions, climatic oscillations are thus a driving force of allopatric speciation: due to phylogenetic niche conservatism (Wiens, 2004), species tend to retain similar ecological niches over time (Ricklefs and Latham, 1992; Peterson et al., 1999, Webb et al., 2002), and their ranges are thus fragmented and reconnected repeatedly through climatic cycles. 
The mountains of the Middle East were not affected by glaciations to the same extent as northern Europe, although at higher altitudes glacial erosive or depositional features have been found (e.g. Akçar \& Schlüchter, 2005). However, it is a fallacy to believe that the Near and Middle East did not experience climatic fluctuations of large magnitude (e.g. Joannin et al., 2010). In mountains, the upper vegetation zone is restricted by the snow line. Today, the habitats of Montivipera populations have their upper elevational limit approximately 800-1500 m below the summer snow line. During last glacial maximum (19-23 ka) the palaeo snowline was estimated to have been $1000 \mathrm{~m}$ below the modern snow line (Sarýkaya, 2011), suggesting that the elevational range of mountain viper species was similarly lowered, leading to range expansion and reconnection for populations of montane species. This explains both, the pattern of allopatric speciation seen between montane forms in separated mountain systems in the bornmuelleri-clade, but also the shallow divergences between currently isolated populations of the raddei-complex.

This Plio-Pleistocene scenario has thus left distinctive marks on the genome (Hewitt, 1996) and initiated vicariant allopatric speciation and dispersal. Allopatric populations, which experienced little gene flow, can be isolated over long time periods, allowing them to acquire and retain unique and high genetic variation (Petit et al., 2003; Hampe and Petit, 2005). During glacial-interglacial episodes the Mediterranean mountains played a key role in speciation processes as refugia (Médail and Diadema, 2009). This hypothesis is also supported by plant diversity-environment relationships in southern Europe (Svenning et al., 2009).

Our results evidently imply restricted gene flow among the populations by the appearance of physical vicariance. This phenomenon of decreasing chances of mating might have been caused by the topographic relief and discontinuous habitats in the Near and Middle East.

Presumably, mountain viper populations survived glacial periods in allopatric refugial areas adjoining mountain chains in the Near and Middle East, or in situ within valley systems of high mountains, with each distinct regional clade having had its own refugium.

Comparable studies are rare for the Near and Middle East. For Asia Minor our results are in concordance with other studies pointing out the impact of Anatolian Mountains for species diversity (e.g. Hewitt, 1999; 2000; Veith et al., 2003; Çiplak, 2003; 2004; Mutun, 2010; Bilgin, 2011) and fit in with the hypothesis of Nilson et al. (1990) that the Anatolian Diagonal is a key factor for diversification of the Montivipera xanthina-complex and a hot spot for other biota (Ekim and Güner, 1986; Duran et al., 2005). It is worth mentioning that, despite their aquatic life history, eastern Mediterranean water frogs (Plötner et al., 2010) show a highly congruent distribution of mthaplotypes with the Anatolian mountain vipers, supporting the broad relevance of vicariant palaeogeological events for the evolution of Eastern Mediterranean biota. Médail and Diadema (2009) identified multiple floral refugia in the Mediterranean mountains, which indicate continuous 
divergence and speciation over many millions of years to the present. The high congruence between the geographic distribution of Montivipera haplotypes and plant refugia (Fig. 8) is astonishing and evidently indicates the importance of common historical events as drivers of speciation and distribution across a broad swath of Near and Middle Eastern biota.

\subsection{Implications for mountain viper systematics and future work}

Translating the phylogeographic results obtained in this study into a formal taxonomic framework remains challenging and subject to multiple different interpretations, depending on the species delimitation criteria used (de Queiroz, 2007). Mountain vipers are allopatrically distributed and inhabit isolated disjunct mountain areas and are therefore genetically and geographically isolated. However, experimental hybridizations between $M$. wagneri and $M$. xanthina result in fertile offspring (own observations). Further research may yet reveal natural hybrid zones, where populations share haplotypes of different species. On the other hand, many isolated populations are clearly geographic variants of one another, but display distinctive phenotypic features, so that no intermediates exist. Speciation is a complex process culminating in the evolution of intrinsic isolation mechanisms, which result in genetic isolation. During the preceding transition time, when populations diverge, it is difficult to find objective criteria for species delimitation (Hey, 2009), because the lineage simply may not yet have evolved distinctive properties. However, the presence of any unique property constitutes evidence for lineage separation and the possession of several properties highly corroborate the existence of different species (De Queiroz, 2007).

Proposals for taxonomic classification of the Montivipera taxa have been made in either the splitting or lumping direction. Nilson and Andrén (1986), who described wagneri, bulgardaghica and albizona as full species, stated that these taxa including bornmuelleri could also be treated as subspecies or allospecies of one superspecies. In line with this argumentation, Montivipera would consist of three species xanthina, bornmuelleri and raddei.

According to the molecular evidence presented in this paper, we suggest to treat each major evolutionary lineage of Montivipera as valid species. Our molecular genealogy supports bornmuelleri, wagneri, bulgardaghica, albizona, raddei, latifii and kuhrangica as valid taxa. They all represent unique evolutionary lineages, separated by considerable genetic distances. The exception are albicornuta and kurdistanica, where we found no evidence for monophyletic origins. Nominal haplotypes of both taxa scatter through the tree and belong to the raddei haplo-group. In the absence of unique morphological characters, albicornuta and kurdistanica should be collapsed into raddei and considered geographic variants of the latter. Montivipera albizona has a unique nuclear haplotype, which separates the taxon from the allopatric bulgardaghica, but the mtDNA genealogy evidently suppose genetic contact between both taxa. Considering the allopatric distribution and similar morphological and ecological synapomorphies, we prefer to treat albizona as a subspecies of 
bulgardaghica. A single specimen from the Syrian Levant represents a new phyletic lineage in the pedigree. However, without any further knowledge and additional specimens, further taxonomic conclusions are hardly possible.

In the light of our genetic data, $M$. xanthina appears to constitute a cryptic species complex with three or four new taxa. Each of them has a long standing history of isolation comparable to the species of the bornmuelleri-clade. Prior to this genetic analysis, a phenotypic distinction between the phyletic xanthina lineages was not possible, probably due to the lack of material. With the phylogenetic background of this study, genetic information is available which can be included for accurate species identification, and can guide the search for morphological characters that can help differentiate these taxa. Taxonomic revisions have different connotations for further biological analysis.

Together with Macrovipera, Montivipera is responsible for serious, often-lethal clinical problems in the Near and Middle East (e.g. Chippaux 1998). Venom composition varies both interspecifically and intraspecifically in many snakes, and this can have severe consequences for snakebite victims (Casewell et al., 2013). Where victims of bites require antivenom, and in the absence of direct evidence on venom composition of antivenom effectiveness, phylogenetic relatedness of lineages could potentially inform antivenom choice. Moreover, the evolutionary tree for a group of species can also inform conservation measures for these taxa.

Future morphological work including more samples is necessary to identify diagnostic characters for species delimitation and to evaluate the species concept made here on the basis of molecular data alone.

\section{Acknowledgments}

This study was generously supported by Erko Stackebrand and Miguel Vences, who provided the laboratory cooperation with the German Collection of Microorganisms and Cell Cultures (DSMZ) and the Technical University of Braunschweig.

Our research was kindly supported by the Volkswagen foundation, Project I/83 987 and Volkswagen Nutzfahrzeuge Hannover by supporting our fieldtrips.

For laboratory assistance we thank Cathrin Spröer, Ina Kramer, Evelyne Brambilla, Gabriele Keunecke and Meike Kondermann. For providing samples we thank Peter van Issem, Selami Tomruk (Ekopark, Tekirova), Joseph Schmidtler, Alexander Westerström, Werner Mayer (NMW), the late Svetlana Kalyabina-Hauf, Hiwa Faizi and Benny Trapp. Ibrahim Baran (Dokuz Eylül Universitesi, Buca Eğitim Fakültesi, Izmir) and Nasrullah Rastegar-Pouyani (Department of Biology, Faculty of Science, Razi Universitesy, Kermanshah, Iran) we thank for collaboration in our project.

We are also grateful to two anonymous reviewers for the careful assessment of the manuscript. 


\section{Literature}

Akçar, N., Schlüchter, C., 2005. Paleoglaciations in Anatolia: a schematic review and first results. Eiszeitalter Gegenwart 55, 102-121.

Andrén C., Nilson, G. 1979. Vipera latifii (Reptilia, Serpentes, Viperidae) an endangered viper from Lar Valley, Iran, and remarks on the sympatric herpetofauna. J. herpetol. 13, 335-341.

Ansell, S.W., Stenøien, H.K., Grundmann, M., Russell, S.J., Koch, M.A., Schneider, H., Vogel, J.C., 2012. The importance of Anatolian mountains as the cradle of global diversity in Arabis alpina, a key arcticalpine species. Ann Bot. 108, 241-252. doi: 10. 1093/aob/mcr134

Antunes, M.T., Rage, J.C. , 1974. Notes sur la géologie et la paléontologie du Miocène de Lisbonne. XIV - Quelques Squamata (Reptilia). Bol. Soc. Geol. Port. 19, 47-60.

Avise, J.C., 2009. Phylogeography: retrospect and prospect. Journal of Biogeography 36, 3-15.

Avise J.C., Walker, D., Johns, G.C., 1998. Speciation durations and Pleistocene effects on vertebrate phylogeography. Proc. R. Soc. Lond B Biol. Sci. 265, 1707-1712.

Barbanera, F., Zuffi, M.A.L., Guerrini, M., Gentilli, A., Tofanelli, S., Fasola, M., Dini, F., 2009. Molecular phylogeography of the asp viper Vipera aspis (Linnaeus, 1758) in Italy: Evidence for introgressive hybridization and mitochondrial DNA capture. Molecular Phylogenetics and Evolution 52, 103-114.

Barraclough, T.G., Vogler, A.P., 2000. Detecting the geographic pattern of speciation from species level phylogenies. Am. Nat. 155, 419-434.

Barry, R.G., 2008. Mountain weather and climate. Cambridge, UK, Cambridge University Press.

Bennett, K.D., 1997. Evolution and ecology: the pace of life. Cambridge University Press.

Benton, M.J., Ayala, F.J., 2003. Dating the tree of life. Science 300, 1698-1700.

Benton, M.J., Donoghue, P.C.J., 2007. Palaeontological evidence to date the tree of life. Mol. Biol. Evol. 24, 26-53.

Bettex, F., 1993. Beobachtungen an Vipera bulgardaghica, Vipera albizona und Vipera xanthina im Freiland und im Terrarium. Herpetofauna 86, 21-26.

Bilgin, R., 2011. Back to the Suture: The distribution of intraspecific genetic diversity in and around Anatolia. Int. J. Mol. Sci. 12, 4080-4103. doi: 10. 3390/ijms12064080

Brodmann, P., 1987. Die Giftschlangen Europas und die Gattung Vipera in Afrika und Asien. Basel: Kümmerly+Frey.

Casewell, N.R., Wüster, W., Vonk, F.J., Harrison, R.A., Fry, B.G., 2013. Complex cocktails: the evolutionary novelty of venoms. Trends in Ecology and Evolution 28 (4), 219-229. doi.org/10.1016/j.tree.2012.10.020

Charlesworth, D., Charlesworth, B., Morgen, M.T., 1995. The pattern of neutral molecular variation under the background selection model. Genetics 141, 1619-32.

Cheylan, M., Poitevin, F., 1994. Conservazione di rettili e anfibi, in: Monbailliu, X., Torre, A. (Eds.), La gestione degli ambienti costieri insulari del Mediterraneo. Edizione del Sole, Alghero, pp. 275-336.

Chippaux, J.-P. 1998. Snake-bites: appraisal of the global situation. Bulletin of the World Health Organization 76 (5), 515-524.

Chippaux, J.-P., Williams, V., White, J., 1991. Snake venom variability: methods of study, results and interpretation. Toxicon 29, 1279-1303.

Çiplak, B., 2003. Distribution of Tettigoniinae (Orthoptera, Tettigoniidae) bush-crickets in Turkey: the importance of the Anatolian Taurus Mountains in biodiversity and implications for conservation. Biodiversity and Conservation 12, 47-64. doi: 10. 1023/A: 1021206732679.

Çiplak, B., 2004. Systematics, phylogeny and biogeography of Anterastes (Orthoptera, Tettigoniidae, Tettigoniinae): evolution within a refugium. Zoologica Scripta 33, 19-44. 
David, P., Vogel, G., 2010. Venomous snakes of Europe northern, central and western Asia. Terralog, Edition Chimaira, Frankfurt/Main.

De Queiroz, K., 2007. Species Concepts and Species Delimitation. Syst. Biol. 56(6), 879-886. doi: 10.1080/10635150701701083

Djamali, M., de Beaulieua, J.-L., Shah-hosseinib, M., Andrieu-Ponela, V., Ponela, P., Aminic, A., Akhanid, H., Leroye, S., Stevensf, L., Lahijanib, H., Brewerg, S., 2008. A late Pleistocene long pollen record from Lake Urmia, NW Iran. Quaternary Research, 69, 413-420.

Drummond, A.J., Suchard, M.A., Dong, X., Rambaut, A., 2012. Bayesian phylogenetics with BEAUti and the BEAST 1. 7. Mol. Biol. Evol. 29, 1969-1973.

Drummond, A.J., Rambaut, A., 2007. BEAST: Bayesian evolutionary analysis by sampling trees. BMC Evol. Biol. 7, 214.

Duran, A., Saðýroðlu ,M., Duman, H., 2005. Prangos turcica (Apiaceae), a new species from South Anatolia, Turkey. Ann. Bot. Fennici 42, 67-72.

Ekim, T., Güner, A., 1986. The Anatolian Diagonal: Fact or fiction. Proc. R. Soc. Edinb. Nat. Environ. 89, 67-77.

Evans, S.E., 2003. At the feet of the dinosaurs: the early history and radiation of lizards. Biol Rev 78: 513-551.

Excoffier, L., Laval, G., Schneider, S., 2005. Arlequin ver. 3.0: an integrated software package for population genetics data analysis. Evolutionary Bioinformatics Online 1, 47-50.

Excoffier, L., Smouse, P., Quattro, J.M., 1992. Analysis of molecular variance inferred from metric distances among DNA haplo-types: application to human mitochondrial DNA restriction data. Genetics $131,479-491$.

Excoffier, L., Schneider, S., 1999. Why hunter-gatherer populations do not show signs of Pleistocene demographic expansions. Proceedings of the National Academy of Sciences, USA 96, 10597-10602.

Ferchaud, A.-L., Ursenbacher, S., Cheylan, M., Luiselli, L., Jelic, D., Halpern, B., Major, A., Kotenko, T., Keyans, N., Behrooz, R., Crnobrnja-Isailovic, J., Tomovic, L., Ghira, I., Ioannidis, Y., Arnal, V., Montgelard, C., 2012. Phylogeography of the Vipera ursinii complex (Viperidae: mitochondrial markers reveal an east-west disjunction in the Palaearctic region. J. Biogeogr. 39 (10), 1836-1847.

Fu, X.Y., 1997. Statistical tests of neutrality of mutations against population growth, hitchhiking, and background selection. Genetics 147, 915-925.

Futuyma, D.J., 1998. Evolutionary biology. 3rd ed. Sunderland, MA: Sinauer Associates.

Galtier, N., Nabholz, B., Glémin, S., Hurst, G.D.D., 2009. Mitochondrial DNA as a marker of molecular diversity: a reappraisal. Mol. Ecol. 18, 4541-4550.

Gandolfo, M.A., Nixon, K.C., Crepet, W.L., 2008. Selection of fossils for calibration of molecular dating models. Ann. Missouri Bot. Gard. 95, 34-42.

Garrigues, T., Daugab, C., Ferquelc, E., Choumetd, V., Faillouxa, A.-B., 2005. Molecular phylogeny of Vipera Laurenti, 1768 and the related genera Macrovipera (Reuss, 1927) and Daboia (Gray, 1842), with comments about neurotoxic Vipera aspis aspis populations. Mol. Phylogent. Evol. 35, 35-47.

Göçmen, B., Mebert, K., İğci, N., Akman, B., Yıldız, M.Z. Oğuz, M. A., Altın, C., 2014. New locality records for four rare species of vipers (Reptilia: Viperidae) in Turkey. Zoology in the Middle East 60 (4), 306-313. doi.org/10.1080/09397140.2014.966518

Golay, P., Smith, H.M., Broadley, D.G., Dixon, J.R., McCarthy, C., Rage, J-C., Schätti, B., Toriba, M., 1993. Endoglyphs and other major venomous snakes of the World. A Checklist. Geneva: Azemiops.

Guindon, S., Dufayard ,J-F., Lefort, V., Anisimova, M., Hordijk, W., Gascuel, O., 2010. PhyML: New Algorithms and Methods to Estimate Maximum-Likelihood Phylogenies: Assessing the Performance of PhyML 3.0. Syst. Biol. 59, 307-321.

Hall, T.A., 1999. BioEdit: a user-friendly biological sequence alignment editor and analysis program for Windows 95/98/NT. Nucleic Acids Symp, Ser, 41, 95-98. 
Hampe, A., Petit, R.J., 2005. Conserving biodiversity under climate change: the rear edge matters. Ecology Letters 8, 461-467.

Hansen, J., Sato, M., 2012: Paleoclimate implications for human-made climate change, in A. Berger, F. Mesinger, Šijači, D., (Eds.), Climate Change at the Eve of the Second Decade of the Century: Inferences from Paleoclimate and Regional Aspects. Proceedings of Milutin Milankovitch 130th Anniversary Symposium.

Head, J.J., 2005: Snakes of the Siwalik Group (Miocene of Pakistan): Systematics and relationship to environmental change. Palaeont. Electronica 8, 1-33.

Hedges, S.B., Kumar, S., 2004. Precision of molecular time estimates. Trends Genet. 20, 242-247.

Herrmann, H-W., Joger, U., Nilson, G., 1992. Phylogeny and systematics of Viperinae snakes. III: Resurrection of the genus Macrovipera (Reuss, 1927) as suggested by biochemical evidence. Amphibia-Reptilia 13, 375-392.

Herrmann, H-W., Joger, U., Nilson, G., Sibley, C.G., 1987. First steps towards a biochemically based reconstruction of the phylogeny of the genus Vipera, in: van Gelder, J.J., Strijbosch, H., Bergers, P.J.M., (Eds.), Nijmegen: Proc. Fourth Ord. Gen. Meet. SEH, pp. 195-200.

Hewitt, G.M., 1996. Some genetic consequences of ice ages, and their role in divergence and speciation. Biol. J. Linn. Soc. 58, 247-276.

Hewitt, G.M., 1999. Post-glacial recolonization of European biota. Biol. J. Linn. Soc. 68, 87-112.

Hewitt, G.M., 2000. The genetic legacy of the quaternary ice ages. Nature 405, 907-913.

Hewitt, G.M., 2004a. Genetic consequences of climatic oscillations in the Quaternary. Phil. Trans. R. Soc. Lond B 359, 183-195. doi 10. 1098/rstb. 2003. 1388

Hewitt, G.M., 2004b. The structure of biodiversity - insights from molecular phylogeography. Frontiers in Zoology 1, 4. doi: 10. 1186/1742-9994-1-4

Hewitt, G.M., 2011. Mediterranean Peninsulas: The Evolution of Hotspots, in: Zachos, F.E., Habel, J.C. (Eds.), Biodiversity Hotspots: Distribution and Protection of Conservation Priority Areas. SpringerVerlag Berlin, Heidelberg pp. 123-147.

Hey, J. 2009. On the arbitrary identification of real species, in: Butlin, R.K., Bridle, J., Schluter, D. (Eds.), Speciation and patterns of diversity. Cambridge Univ. Press, Cambridge, UK, pp. 15-28.

Hofreiter, M., Stewart, J., 2009. Ecological change, range fluctuations and population dynamics during the Pleistocene. Current Biology 19, R584-R594. doi 10. 1016/j. cub. 2009. 06. 030

Holt, R.D., 1996. Demographic constraints in evolution: towards unifying the evolutionary theories of senescence and niche conservatism. Evol. Ecol. 10, 1-11.

Holt, R.D., Gaines, M.S., 1992. Analysis of adaptation in heterogeneous landscapes: implications for the evolution of fundamental niches. Evol. Ecol. 6, 433-447.

Hungerer, K.B., Kadereit, J.W., 1998. The phylogeny and biogeography of Gentiana L. sect. Ciminalis (Adans.) Dumort.: a historical interpretation of distribution ranges in the European high mountains. Perspectives in Plant Ecology. Evolution and Systematics 1, 121-135.

Joannin, S. J.-J., Cornée, P., Münch, M., Fornari, I., Vasiliev, W., Krijgsman, S., Nahapetyan, I., Gabrielyan, V., Ollivier, P., Roiron, C., Chataigner, 2010. Early Pleistocene climate cycles in continental deposits of the Lesser Caucasus of Armenia inferred from palynology, magnetostratigraphy, and 40Ar/39Ar dating. Earth and Planetary Science Letters 291, 149-158.

Joger, U., 1984. The Venomous Snakes of the Near and Middle East. Beihefte zum Tübinger Atlas des Vorderen Orients, Reihe A, Nr. 12, in: Reichert L. (Eds.), Beihefte zum Tübinger Atlas des Vorderen Orients, Vol. 12. Naturwissenschaften, Wiesbaden, pp. 1-115.

Joger, U., 2005. Montivipera Nilson, Tuniyev, Andrén, Orlov, Joger, Herrmann, 1999, in: Joger, U., Stümpel, N. (Eds.), Handbuch der Reptilien und Amphibien Europas, Schlangen (Serpentes) III. AulaVerlag, Wiebelsheim, pp. 61-62. 
Joger, U., Teynié, A., Fuchs, D., 1988. Morphological characterization of Vipera wagneri Nilson \& Andrén, 1984 (Reptilia: Viperidae), with first description of the males. Bonn. zool. Beitr. 39, 221-228.

Joger, U., Fritz, U., Guicking, D., Kalyabina-Hauf, S., Nagy, Z.T., Wink, M., 2007. Phylogeography of western Palaearctic reptiles - Spatial and temporal speciation patterns. Zoologischer Anzeiger 246, 293-313.

Krupp, F., Khalaf, M., Malek, M., Streit, B., Al-Jumaily, M., 2009. The Middle Eastern Biodiversity Network: Generating and sharing knowledge for ecosystem management and conservation. ZooKeys 31, 3-15. doi: 10. 3897/zookeys. 31. 371

Kubatko, L.S., Degnan, J.H., 2007. Inconsistency of Phylogenetic Estimates from Concatenated Data under Coalescence. Syst. Biol. 56(1),17-24.

Lanfear, R., Calcott, B., Ho, S.Y.W., Guindon, S., 2012. PartitionFinder: combined selection of partitioning schemes and substitution models for phylogenetic analyses. Mol. Biol. Evol. 29 (6), 16951701. doi.org/10.1093/molbev/ mss020.

Lemmon, A.R., Lemmon, E.M., 2008. A likelihood framework for estimating phylogeographic history on a continuous landscape. Syst. Biol. 57, 544-561.

Lenk, P., Kalyabina, S., Wink, M., Joger, U., 2001. Evolutionary relationships among the true vipers (Viperinae) inferred from mitochondrial DNA sequences. Mol. Phylogent. Evol. 19, 94-104.

Lieberman, B.S., 2002. Phylogenetic biogeography with and without the fossil record: gauging the effects of extinction and palaeontological incompleteness. Palaeogeogr. Palaeoclimatol. Palaeoecol. 178, 39-52.

Losos, J.B., 2008. Phylogenetic niche conservatism, phylogenetic signal and the relationship between phylogenetic relatedness and ecological similarity among species Ecology Letters 11, 995-1007. doi: 10.1111/j.1461-0248.2008.01229.x

Lukoschek, V., Keogh, J.S., Avise, J.C., 2012. Evaluating fossil calibrations for dating phylogenies in light of rates of molecular evolution: a comparison of three approaches. Syst. Biol. 61, 22-43

Lynch, V. J., Wagner, G.P., 2010. Did egg-laying boas break Dollo's law? Phylogenetic evidence for reversal to oviparity in sand boas (Eryx: Boidae). Evolution 64, 207-216.

McVay, J.D., Carstens, B.C., 2013. Phylogenetic Model Choice: Justifying a Species Tree or Concatenation Analysis 1(3). doi.org/10.4172/2329-9002.1000114

Mebert, K. , Göçmen, B , İğci, N. , Oğuz M.A., Kariş. M., Ursenbacher, S. 2015. New records and search for contact zones among parapatric vipers in the genus Vipera (barani, kaznakovi, darevskii, eriwanensis), Montivipera (wagneri, raddei), and Macrovipera (lebetina) in northeastern Anatolia. Herpetological Bulletin 133, 13-22.

Médail, F., Diadema, K., 2009. Glacial refugia influence plant diversity patterns in the Mediterranean Basin. Journal of Biogeography 36, 1333-1345.

Médail, F., Myers, N., 2004. Mediterranean Basin. Hotspots revisited: Earth's biologically richest and most endangered terrestrial ecoregions, in: Mittermeier, R.A., Robles, P., Hoffmann, G.M., Pilgrim, J., Brooks, T., Mittermeier, C.G., Lamoreaux, J., da Fonseca, G.A.B. (Eds.), CEMEX, Monterrey, Conservation International. Washington and Agrupación Sierra Madre, Mexico pp. 144-147.

Mertens, R., 1967. Über Lachesis libanotica und den Status von Vipera bornmuelleri. Senck. biol. 48, 153-159.

Mertens, R., Darevsky, I.S., Klemmer, K., 1967. Vipera latifii, eine neue Giftschlange aus dem Iran. Senck. biol. 48, 161-168.

Milankovitch, M., 1941. Canon of insolation and the ice-age problem. Royal Serbian Academy, Special Publication No. 132, translated from German by Israel Program for Scientific Translations, Jerusalem, 1969.

Mosbrugger, V., Utescher, T., Dilcher, D.L., 2005. Cenozoic continental climatic evolution of Central Europe. PNAS 42, 14964-14969. 
Müller, .J, Reisz, R.R., 2005. Four well-constrained calibration points from the vertebrate fossil record for molecular clock estimates. Bioessays 27, 1069-1075.

Mutun, S., 2010. Intraspecific genetic variation and phylogeography of the oak gallwesp Andricus caputmedusae (Hymenoptera: Cynipidae): Effects of the Anatolian Diagonal. Acta Zool. Academ. Sci. Hung 56, 153-172.

Nilson, G., Andrén, C., 1984. Systematics of the Vipera xanthina complex (Reptilia: Viperidae) II. An overlooked viper within the xanthina species-group in Iran. Bonner Zoologische Beiträge 35, 175-184.

Nilson, G., Andrén, C., 1986. The Mountain vipers of the Middle East - The Vipera xanthina complex (Reptilia, Viperidae). Bonner Zoologische Monographien 20. Bonn: Zoologisches Forschungsinstitut und Museum Alexander Koenig.

Nilson, G., Andrén, C., 1992. The species concept in the Vipera xanthina complex: reflecting evolutionary history or hiding biological diversity?. Amphibia-Reptilia 13, 421-424.

Nilson, G., Andrén, C., Flärdh, B., 1990. Vipera albizona, a new mountain viper from central Turkey, with comments on isolating effects of the Anatolian „Diagonal“. Amphibia-Reptilia 11, 285-294.

Nilson, G., Andrén, C., 1979. Vipera latifii (Reptilia, Serpentes, Viperidae) an endangered viper from Lar Valley, Iran, and remarks on the sympatric herpetofauna. Journal of Herpetology 13 (3), 335-341.

Nilson, G., Tuniyev, B., Andrén, C., Orlov, N., Joger, U., Herrmann, H-W., 1999. Taxonomic position of the Vipera xanthina complex. Kaupia, Darmstädter Beiträge zur Naturgeschichte 8, 99-102.

Nylander, J.A.A., 2004. MrModeltest v2. Programm distributed by the author. Evolutionary Biology Center, Uppsala University (http: //www. abc. se/ nylander/).

Obst, F.J., 1982. Zur Kenntnis der Schlangengattung Vipera. Zool. Abh. staatl. Mus. Tierk. Dresden 38, 229-235.

Ozay, G., Bosnak, M., Ece, A., Davutoglu, M., Dickici, B., 2005. Clinical characteristics of children with snake bite poisoning and management of complications in the PICU. Pediatr. Int. 47, 669-675.

Paillard, D., 2001. Glacial cycles: toward a new paradigm. Reviews of Geophysics 39, 325-346.

Padian, K., Lindberg, D.R., Polly, P.D., 1994. Cladistics and the fossil record: The Uses of History. Annu. Rev. Earth Planet. Sci. 22, 63-91.

Parolly, G., 2004. The high mountain vegetation of Turkey - a state of the art report, including a first annotated conspectus of the major syntaxa. Turk J. Bot. 28, 39-63.

Peterson, A.T., Soberón J., Sanchez-Cordero, V., 1999. Conservatism of ecological niches in evolutionary time. Science 285, 1265-1267.

Petit, R.J., Aguinagalde, I., de Beaulieu, J.-L., Bittkau, C., Brewer, S., Cheddadi, R., Ennos, R., Fineschi, S., Grivet, D., Lascoux, M., Mohanty, A., Müller-Starck, G., Demesure-Musch, B.,Palmé, A., Martín, J.P., Rendell, S., Vendramin, G.G., 2003. Glacial refugia: hotspots but not melting pots of genetic diversity. Science 300, 1563-1565.

Phelps, T., 2010. Old world vipers - A Natural History of the Azemiopinae, and Viperinae. Edition Chimaira, Frankfurt/Main.

Plötner, J., Uzzell, T., Beerli, P., Akým, C., Biligin, C.C., Haefeli, C., Ohst, T., Köhler, F., Schreiber, R., Guex, G-D., Litvinchuk, S.N., Westaway, R., Reyer, H-U., Pruvost, N., Hotz, H., 2010. Genetic divergence and evolution of reproductive isolation in Eastern Mediterranean water frogs, in: Glaubrecht, M., (Eds.), Evolution in action. Springer, Heidelberg, pp. 373-399.

Poisson, A., Orszag-Sperber, F., Kosun, E., Bassetti, M.-A., Müller, C., 2011. The Late Cenozoic evolution of the Aksu basin (Isparta Angle; SW Turkey). New insights. Bull. Soc. Géol. Fr. 182, 133-148. doi: 10. 2113/gssgfbull. 182. 2.133"

Popov, S.V., Rögl, F., Rozanov, A.Y., Steininger, F.F., Shcherba, I.G., Kovac, M., 2004. Lithologicalpalaeogeographic maps of Paratethy, 10 maps Late Eocene to Pliocene. E. Schweizerbart'sche Verlagsbuchhandlung (Nägele u. Obermiller), Stuttgart. 
Rage, J-C., Buffetaut, E., Buffetaut-Tong, H., Chaimanee, Y., Ducrocq, S., Jaerger, J-J., Suteethorn, V., 1992. A colubrid snake in the late Eocene of Thailand: the oldest known Colubridae (Reptilia, Serpentes). C. R. Acad. Sci. Paris, II 314, 1085-1089.

Rajabizadeh. M., Nilson, G., Kami, H.G., 2011. A new species of mountain viper (Ophidia: Viperidae) from the central Zagros Mountains, Iran. Russ. J. Herp 18, 235-240.

Rambaut, A., Drummond, A.J., 2007. Tracer v1. 4. Available from: http: //beast. bio. ed. ac. uk/Tracer.

Ricklefs, R.E., Latham, R.E., 1992. Intercontinental correlation of geographical ranges suggests stasis in ecological traits of relict genera of temperate perennial herbs. Am. Nat. 139, 1305-1321.

Rogers, A.R., Harpending, H., 1992. Population growth makes waves in the distribution of pairwise genetic differences. Molecular Biology and Evolution 9, 552-569.

Rogers, A.R., Fraley, A.E., Bamshad, M.J., Watkins, W.S., Jorde, L.B., 1996. Mitochondrial mismatch analysis is insensitive to the mutational process. Mol. Biol. and Evol. 13, 895-902.

Rögl F., 1999. Mediterranean and Paratethys. Facts and hypotheses of an Oligocene to Miocene palaeogeography (short overwiev). Geologica Carpathica 50, 339-349.

Ronquist, F., Huelsenbeck, J.P., 2003. MrBayes 3: Bayesian phylogenetic inference under mixed models. Bioinformatics 19, 1572-1574.

Şapaş A., Boztepe-Güney A., 2009. Shear wave splitting in the Isparta Angle, southwestern Turkey: Anisotropic complexity in the mantle. J. Earth Syst. Sci. 118, 71-80.

Sarýkaya, M.A., Çiner, A., Zreda, M., 2011. Quaternary glaciations of Turkey, in: Ehlers, J., Gibbard, P.L., Hughes, P.D. (Eds.), Developments in Quaternary Science 15. Elsevier, Amsterdam, pp. 393-403.

Schätti, B., Baran, I., Sigg, H., 1991. Rediscovery of the Bolkar viper: morphological variation and systematic implication on the "Vipera xanthina complex". Amphibia-Reptilia 12, 305-327.

Schätti, B., Baran, I., Sigg, H., 1992. The 'Vipera xanthina complex' - a reply to Nilson and Andrén. Amphibia-Reptilia 13, 425-425.

Schmitt, T., 2009. Biogeographical and evolutionary importance of the European high mountain systems. Front. Zool. 6, 9. doi: 10. 1186/1742-9994-6-9

Schwarz, E., 1936. Untersuchungen über Systematik und Verbreitung der europäischen und mediterranen Ottern. Behringwerk-Mitteilungen 7, Marburg a. d. Lahn, pp. 159-362.

Sindaco, R.G., Menegon, S.,M., 2006. New data on the Syrian herpetofauna, with a newly-recorded species of snake. Zoology in the Middle East 37, 29-38.

Slatkin, M., Hudson, R.R., 1991. Pairwise comparisons of mitochondrial DNA sequences in stable and exponentially growing populations. Genetics 129, 555-562.

Stephens, M., Scheet, P., 2005. Accounting for decay of linkage disequilibrium in haplotype inference and missing data imputation. American Journal of Human Genetics 76, 449-462.

Stephens, M., Smith, N.J., Donnelly, P., 2001. A new statistical method for haplotype reconstruction from population data. American Journal of Human Genetics 68, 978-989.

Stümpel, N., 2012. Phylogenie und Phylogeographie eurasischer Viperinae unter besonderer Berücksichtigung der orientalischen Vipern der Gattungen Montivipera und Macrovipera. PhD-Thesis, TU Carolo-Wilhelmina zu Braunschweig.

Stümpel, N., Joger, U., 2009. Recent advances in phylogeny and taxonomy of Near and Middle Eastern Vipers - an update. ZooKeys 31, 179-191.

Svenning, J-C., Skov, F., 2007. Ice age legacies in the geographical distribution of tree species richness in Europe. Global Ecol. Biogeogr. 16, 234-245.

Svenning, J.-C., Normand, S., Skov, F., 2009. Plio-Pleistocene climate change and geographic heterogeneity in plant diversity-environment relationships. Ecography 32,13-21.

Szyndlar, Z., Rage, J-C., 1990. West Palearctic cobras of the genus Naja (Serpentes: Elapidae): interrelationships among extinct and extant species. Amphibia-Reptilia 11, 385-400. 
Szyndlar, Z., Rage, J-C., 1999. Oldest fossil vipers (Serpentes: Viperidae) from the Old World. Kaupia 8, 9-20.

Taberlet, P., Fumagalli, L., Wust-Saucy, A-G., Cosson, J-F., 1998. Comparative phylogeography and postglacial colonization routes in Europe. Molecular Ecology 7, 453-464.

Tajima, F., 1989. Statistical method for testing the neutral mutation hypothesis by DNA polymorphism. Genetics 123, 585-595.

Teynié, A., 1987. Observations herpetologique en Turquie, 1ere Partie. J. Bull. Soc. Herp. Fr. 43, 9-18.

Teynié, A., 1991. Observations herpetologique en Turquie, 2ème Partie. J. Bull. Soc. Herp. Fr. 58, 2130.

Thompson, J.D., Higgins, D.G., Gibson, T.J., 1994. CLUSTAL W: improving the sensitivity of progressive multiple sequence alignment through sequence weighting, positions-specific gap penalties and weight matrix choice. Nucleic Acids Res. 22, 4673-4680.

Tolley, K.A., Townsend, T.M., Vences, M., 2013. Large-scale phylogeny of chameleons suggests African origins and Eocene diversification. Proc. R. Soc. B 280 no. 1759. doi: 10.1098/rspb.2013.0184

Turelli, M., Barton, N.H., Coyne, J.A., 2001. Theory and speciation. Trends Ecol. Evol. 16, 330-343.

Ursenbacher, S., Conelli, A., Golay, P., Monney, J.-C., Zuffi, M.A.L., Thiery, G., Durand, T., Fumagalli, L., 2006. Phylogeography of the asp viper (Vipera aspis) inferred from mitochondrial DNA sequence data: Evidence for multiple Mediterranean refugial areas. Molecular Phylogenetics and Evolution 38, 546552.

Ursenbacher, S., Carlson, M., Helfer, V., Tegelström, H., Fumagalli, L., 2006a. Phylogeography and Pleistocene refugia of the adder (Vipera berus) as inferred from mitochondrial DNA sequence data. Molecular Ecology 15, 3425-3437. doi: 10.1111/j.1365-294X.2006.03031.x

Ursenbacher, S., Schweiger, S., Tomović, L., Crnobrnja-Isailović, J., Fumagalli, L., Mayer, W., 2008. Molecular phylogeography of the nose-horned viper (Vipera ammodytes, Linnaeus (1758)): Evidence for high genetic diversity and multiple refugia in the Balkan peninsula. Molecular Phylogenetics and Evolution 46, 1116-1128.

Van Hinsbergen, D.J.J., Dekkers, M.J., Koç, A., 2010. Testing Miocene remagnetization of Bey Daðlarý: Timing and amount of Neogene rotations in SW Turkey. Turkish J. Earth. Sci. 19, 123-156.

Varga, Z., Schmitt, T., 2008. Types of oreal and oreotundral disjunctions in the western Palearctic. Biol. J. Linn. Soc. Lond 93, 415-430.

Veith, M., Schmidtler, J.F., Kosuch, J., Baran, I., Seitz, A., 2003. Palaeoclimatic changes explain Anatolian mountain frog evolution: a test for alternating, vicariance and dispersal events. Mol. Ecol. 12, 185-199.

Vidal, N., Hedges, S.B., 2005. The phylogeny of squamate reptiles (lizards, snakes, and amphisbaenians) inferred from nine nuclear protein-coding genes. C. R. Biologies 328, 1000-1008.

Webb, C.O., Ackerly, D.D., McPeek, M.A., Donoghue, M.J., 2002. Phylogenies and community ecology. Annu. Rev. Ecol. Syst. 33, 475-505.

Weiss, S., Ferrand, N. (Eds.), 2007. Phylogeography of southern European refugia. Springer, Dodrecht.

Wiens, J.J., 2004. Speciation and ecology revisted: Phylogenetic niche conservatism and the origin of species. Evolution 58, 193-197.

Wiens, J.J., Ackerly, D.D., Allen, A.P., Anacker, B.L., Buckley, L.B., Cornell, H.V., Damschen, E.I., Davies, T.J., Grytnes, J-A., Harrison, S.P., Hawkins, B.A., Holt, R.D., McCain, C.M., Stephens, P.R., 2010. Niche conservatism as an emerging principle in ecology and conservation biology. Ecol. Lett. 13, 1310-1324. doi: 10. 1111/j. 1461-0248. 2010. 01515. x

Wüster, W., Golay, P., Warrell, D.A., 1997. Synopsis of recent developments in venomous snake systematics, No 2. Toxicon 36, 299-307.

Wüster, W., Peppin, L., Pook, C., Walker, D.E., 2008. A nesting of vipers: Phylogeny and historical biogeography of Viperidae (Squamata: Serpentes). Mol. Phylogent. Evol. 49, 445-459. 
Zachos, J., Pagani, M., Sloan, L., Thomas, E., Billups, K., 2001. Trends, Rhythms, and Aberrations in global climate $65 \mathrm{Ma}$ to present. Science 292, 686-693.

Zinenko, A., Stümpel, N., Mazanaeva, L., Bakiev, A., Shyryaev, K., Pavlov, A., Kotenko, T., Kukushkin, O., Chikin, Y., Duisebajeva, T., Nilson, G., Orlov N.L., Tuniev, S., Ananjeva, N.B., Murphy R.W., Joger, U., 2015. Mitochondrial phylogeny shows multiple independent ecological transitions and northern dispersion despite of Pleistocene glaciations in meadow and steppe vipers (Vipera ursinii and Vipera renardi). Molecular Phylogenetics and Evolution 84, 85-100. 